\title{
CAPÍtulo IX \\ EL POSCONFLICTO EN COLOMBIA: \\ UNA OPORTUNIDAD PARA LA CONSTRUCCIÓN DE LA \\ LIBERTAD DESDE LAS HUMANIDADES
}

Guillermo Gómez Agudelo

\section{Introducción}

El presente capítulo destaca la importancia estratégica de los derechos humanos como condición sine qua non, para la ampliación de las libertades, capacidades y oportunidades de los colombianos de cara a una sociedad de posconflicto y el papel destacado que en ello puede cumplir la educación superior y la universidad. Para ello, se acude en primer lugar a caracterizar

1 Licenciado en Ciencias Sociales, Universidad Pedagógica Nacional. Abogado, Universidad Nacional de Colombia. Especialista en Filosofía de la Ciencia, Universidad El Bosque, Bogotá. Magíster en Derechos Humanos, Estado de Derecho y Democracia en Iberoamérica, Universidad Alcalá de Henares. Ha sido profesor de la Facultad de Gobierno y Relaciones Internacionales de la Universidad del Rosario; de la Facultad de Derecho de la Universidad Autónoma de Colombia; de la Facultad de Derecho y Relaciones Internacionales de la Fundación Universitaria Los Libertadores; de la Facultad de Educación de la Universidad el Bosque. 
el origen, naturaleza, evolución y transformación reciente de este discurso; posteriormente se le aborda desde los planteamientos de la perspectiva igualitarista defendida por Ernst Tugendhat en el contexto de nuestra Constitución, para finalizar haciendo una reflexión sobre las ventajas y desafíos de esta perspectiva teórica para la construcción de la paz en Colombia, fundada en la justicia y el respeto por la dignidad del ser humano y sus comunidades y en el que la universidad como formadora de la masa crítica de la sociedad está llamada a cumplir un papel protagónico mediante la formación humanística.

En un contexto de pobreza e inequidad social que mantiene marginada a buena parte de la población colombiana del acceso a la educación y con ella a las ventajas de la ciencia, la técnica y el desarrollo del pensamiento, de tal manera que nos permita construir el futuro que queremos, unido a la gravedad del conflicto armado interno, a la profunda crisis de derechos humanos que ha derivado en crisis humanitaria con más de cinco millones de refugiados internos y externos ${ }^{2}$ - lo que coarta toda posibilidad en el ejercicio de las libertades y ha hecho imperiosa la búsqueda urgente a una salida al conflicto armado en medio de la guerra - , corresponde a la universidad, en su triple función de espacio para la construcción de saber a través de la investigación, la docencia y la proyección social, continuar insistiendo en la comprensión, difusión y exigencia de respeto y protección a los derechos humanos como principal garantía y soporte a una paz duradera y confiable. Tal búsqueda debe realizarse en un claro compromiso con las comunidades y sus problemas en la transformación del país de cara a un escenario distinto y esperanzador de posconflicto.

Sin lugar a dudas, son muchos los retos que deberemos afrontar los colombianos si logramos dar un salto cualitativo hacia la paz. Ello pasa por reconocer que la salida negociada al conflicto armado es apenas la puerta de entrada a una larga tarea de transformaciones y cambios urgentes, dentro de los cuales consideramos como prioritaria la identificación, promoción, restitución y garantía de los derechos humanos, desconocidos o negados durante décadas a millones de colombianos. Pues resulta claro que los derechos humanos, a pesar de las críticas introducidas por el multiculturalismo, el pluralismo jurídico y otras corrientes filosóficas, dejan entrever desde sus orígenes en el siglo XV y XVI las aspiraciones de millones de hombres y mujeres en el mundo que claman por mayores niveles de libertad, justicia social y democracia. En otras palabras, por el respeto a la dignidad humana. Ello explica por qué los Derechos Humanos desde las llamadas revoluciones burguesas, se van a convertir en pieza clave del constitucionalismo moderno y razón

2 Véase al respecto: Amnesty International, The Human Rights Situation in Colombia: Amnesty International's written statement to the 25 th session of the UN Human Rights Council (3-28 March 2014), http://www.amnesty.org/es/library/asset/AMR23/008/2014/es/9cc8391b-1316-4b2f-8df2 ae5106532c0c/ amr230082014en.pdf 
de ser de la organización jurídica y política del Estado de Derecho, hoy convertido en Estado social. Es lo que Ernst Tugenthat, desde el igualitarismo, ha sintetizado como la lucha por una sociedad libre de coacción, dotada de amplias capacidades para proveer a sus miembros una vida digna y capaz de garantizarles cada vez mayores espacios de oportunidad en las que sea posible su participación y decisión en la vida social y política.

\section{Origen, concepto, evolución y transformación reciente de los Derechos Humanos}

Sin temor a equívocos, podría considerarse que la historia de los derechos humanos como claro reflejo de concepciones morales, teológicas y filosóficas en torno al ser humano y a la sociedad en cada época, corre paralela con la evolución de la forma Estado. Así, del Estado del despotismo, propio del Ancien Régime, en el que se privilegia más los intereses de la sociedad que los del individuo, se va a dar paso al Estado de Derecho en el que los derechos humanos serán concebidos, bajo la doctrina del derecho natural, como norte y límite al poder político, quien funda su razón de ser y su legitimidad en la capacidad para garantizar las libertades de los individuos. Posteriormente esta forma Estado se transformará en Estado Democrático de Derecho como producto de los movimientos en Europa que luchan por mayores niveles de participación en la conformación de la voluntad del Estado, lo que finalmente va a desembocar en el llamado Estado Social de Derecho, heredero del socialismo y que recoge en buena parte las reivindicaciones sociales y las luchas del movimiento obrero en favor de la justicia material, más allá del formalismo individual defendido por el pensamiento liberal. Esta forma de Estado aún continúa en gran medida como una aspiración de materialización para miles de seres humanos en el mundo.

Así pues, los derechos humanos son un concepto histórico surgido en Europa con el despertar de la modernidad (siglos XV y XVI), aunque desde sus orígenes hasta nuestros días se ha ido transformando, atendiendo no solo los diversos contextos de realización, sino la forma en que se les ha entendido desde el punto de vista teórico y político. Dicho concepto aparece inicialmente asociado al individualismo que pregona la dignidad humana en contraste con el interés de la sociedad, de ahí que tengan su florecimiento en Europa, en los comienzos de la modernidad, pues en el largo periodo de la época antigua y medieval se consideraba que la persona estaba la comunidad, la cual primaba sobre el individuo, quien no tenía otra alternativa que someterse a los designios de aquella. Pero con las transformaciones sufridas por la vieja 
sociedad medieval y el despertar del mundo moderno, un cierto individualismo se apodera del espíritu de la época. Como bien lo señala Mardones ${ }^{3}$ :

Esta especial sensibilidad por la dignidad de la persona humana es algo que ni la antigüedad ni la sociedad medieval logró desarrollar. Nótese cómo Aristóteles, a pesar de que adelanta algunas ideas en La Política, en relación con el individualismo, en su obra, justifica claramente la esclavitud. Así en su obra dice Aristóteles. Si las citaras se tocaran solas no habría necesidad de Esclavos. ${ }^{4}$

Tal vez durante la edad media se lograron mayores avances en esta materia en sus exigencias al poder político expresadas en lo que significó el documento de la Carta Magna; sin embargo, como bien lo advierte Guillermo Escobar, se trata de una serie de reivindicaciones en favor de individuos no tanto por su condición de personas, sino por su pertenencia a un grupo social determinado 5 . Por eso, según el autor, no se puede hablar aún de derechos humanos en sentido estricto.

Lo anterior nos lleva a pensar que los derechos humanos son un producto de las transformaciones sociales, políticas y religiosas propias de la modernidad, junto con los cambios sufridos en el terreno de la moral, el derecho, la religión y el Estado. En Efecto, ya desde el humanismo se destaca una clara confianza en las capacidades del ser humano. Obsérvese como Giovanni Pico Della Mirandola en su famosa "Oración por la dignidad del hombre" le atribuye a este una capacidad similar a la de la divinidad: la capacidad creadora. En el mismo sentido, para el siglo XV, Bartolomé de las Casas va a denunciar los horrores de la conquista de América y se va a oponer a que a los indios sean asimilados a la condición de esclavos por naturaleza, reivindicando para ellos su identidad sustancial con el resto de los seres humanos. Lo propio hizo Francisco de Vitoria cuando reivindicó los títulos de propiedad de los indios sobre sus tierras y cuestionó la legitimidad del proceso de conquista ${ }^{6}$.

Todas estas transformaciones en torno a la concepción del ser humano necesariamente van a ir acompañadas de cambios profundos en el campo de la filosofía política y su manera de

3 José Mardones, Filosofía de las Ciencias Humanas y Sociales. Materiales para una fundamentación cientifica (Barcelona: Anthropos, 1982).

4 Viktor Pokrovsky, (Carlos Marín, Trad.), Historia de las ideas politicas (México: Grijalbo, 1966)

5 Curso Derechos Humanos. Programa Regional de Apoyo a las Defensorías del Pueblo en Iberoamérica consultado el 26 de noviembre de 2014 en http://cursos.pradpi.org

6 Ibíd., 2. 
entender el poder. Así pues, con la obra de Hugo Grocio, el Estado deja de ser considerado un ente metafísico de carácter divino para ser visto, ahora, como una obra de la creación humana al servicio de determinados fines sociales. ${ }^{7}$

Unido a lo anterior, la lucha por la tolerancia religiosa en medio de las guerras de religión propias de la Europa del siglo XVI y XVII, en procura de superar el fanatismo surgido de la reforma y la contrarreforma, tornan urgente la búsqueda de medidas para evitar la guerra, lo que explica el surgimiento del edicto de Nantes de 1598, el cual otorga a los calvinistas franceses el derecho a la libertad de cultos y el acceso a los cargos públicos en condiciones de igualdad frente a los católicos.

Aunque todos estos avances no se refieren directamente a los derechos humanos, van a constituir una pieza clave para poner límites al poder político y convertir al Estado en un instrumento al servicio del ser humano y de la sociedad, como bien lo reafirmará posteriormente el iusnaturalismo racionalista.

Es tal vez John Locke el que da el paso definitivo hacia esta idea de tolerancia religiosa, al mostrarse en favor de la autonomía del individuo en este terreno, sin más límite que los derechos de los demás. Lo que da cuenta de la madurez del pensamiento de la época para admitir la "autonomía moral y la libertad de conciencia" como el primero de los derechos humanos reconocidos.

Así pues, derechos humanos tienen su origen en el seno de la tradición iusnaturalista, como derechos naturales, lo que supone una concepción distinta del derecho natural que ya no depende de la razón divina como lo consideraba Tomás de Aquino, sino del estado de naturaleza que la razón humana debe descubrir. Tales derechos para esta concepción son anteriores y superiores a todo orden político, pues todo ser humano por el hecho mismo de existir, tiene derecho a que se le trate como un igual y a que se le respete la vida, la libertad, y la propiedad. La garantía de tales derechos va a ser la razón de ser del orden político.

Estas ideas, surgidas inicialmente de Grocio y Locke van a ser desarrolladas posteriormente por Kant. Así, los derechos naturales se van a convertir en el norte y el límite del poder político. Son el norte porque, como ya lo seńalamos, constituyen la razón de ser de la organización del poder y de su garantía va a depender en gran medida la legitimidad de este, y son el límite al convertirse en la barrera de protección de las personas frente al poder del Estado. De acuerdo con el pensamiento liberal de la época, un mayor límite a la intromisión del Estado en los asuntos individuales significa a su vez mayores niveles de libertad para cada persona; lo que lleva a
7 Ibíd., 3.
8 Ibíd., 3. 
pregonar la idea de un Estado mínimo, así como el principio de separación de poderes planteada primero por Locke y luego desarrollada por Montesquieu, junto a la del Estado y la sociedad.

Sin embargo, esta postura va a ser criticada más adelante por Marx, pues resulta ser una concepción individualista y formal que sustrae al individuo de su contexto histórico, con lo que termina por defender libertades meramente individuales que no dan cabida a los derechos sociales, sin los cuales prácticamente el desarrollo de la vida del sujeto no resulta posible.

Ahora bien, la idea de un poder político al servicio de la realización de los derechos naturales resulta acorde con la vieja idea del contrato social de Rousseau, en la que la libertad natural del ser humano debe transformarse en libertad política a partir del acuerdo entre individuos que renuncian a parte de su libertad en beneficio de la libertad general. De esta forma surgen ahora los derechos civiles condensados en la declaración de los Derechos del Hombre y del Ciudadano de 1789, la cual establece claramente que el ejercicio de los derechos naturales no tiene más límites que el ejercicio de los mismos por los demás miembros de la sociedad.

Con esto se condensan dos ideas centrales en la primera concepción de los derechos humanos: la tensión entre iusnaturalismo y contractualismo, con la ventaja de que, gracias a esta elaboración teórica, la libertad ya no se concibe en forma negativa como límite al poder político, sino que ahora se amplía el abanico de derechos y se exige el derecho a la participación en las decisiones que se toman desde el poder. Pero queda claro para la burguesía que los derechos humanos tienen una base racional y no consensual, de ahí que el contractualismo no puede coartar la libertad. Así mismo, los derechos de participación son de naturaleza civil y no natural y por tanto pertenecen a los ciudadanos y no a todas las personas.

Esta tensión entre derecho natural y contractualismo va a quedar plasmada tanto en la Declaración de Derechos de Virginia de 1776 como en la Declaración de los Derechos del Hombre y del Ciudadano de 1789 y va a incidir profundamente en el constitucionalismo moderno, que da al traste con el Estado absoluto e instaura el Estado de Derecho al dejar en claro que los derechos naturales - no creados, sino simplemente declarados por el poder constituyente —, no pueden ser desconocidos por los poderes artificiales, pues de ser así el pueblo debe abrazar el más sagrado de los derechos, el derecho a la insurrección. Lo anterior se desprende del artículo primero de la Declaración de Virginia cuando señala:

"I. Que todos los hombres son por naturaleza igualmente libres e independientes y tienen ciertos derechos innatos, de los que, cuando entran en estado de sociedad, no pueden privar o desposeer a su posteridad por ningún pacto, a saber: el goce de la vida y de la libertad, con los medios de adquirir y poseer la propiedad y de buscar y obtener la felicidad y la seguridad." [Y el artículo 
II al declarar] "que todo poder es inherente al pueblo y, en consecuencia procede de él; que los magistrados son sus mandatarios y sus servidores, y en cualquier momento, responsables ante él. ${ }^{9}$

A pesar de sus avances, esta nueva concepción de Estado como Estado de Derecho va a consagrar un catálogo mínimo de derechos, centrados básicamente en la idea de seguridad, libertad y propiedad, en los que al Estado le corresponde mantener las libertades, pero sin que sea posible hablar de derechos sociales o de una acción positiva del Estado en favor de aquellos; la libertad se sigue entendiendo en forma negativa, es decir, como un límite al poder del Estado. Sin embargo, con estas dos declaraciones de derechos, los derechos humanos van a dejar de ser meras declaraciones de principios y aspiraciones políticas de los individuos para convertirse en fuente de legitimación del poder político y verdaderas exigencias al Estado garantizadas desde los textos constitucionales.

No obstante, las aspiraciones del liberalismo como proyecto revolucionario se van a ver en gran medida truncadas a medida que pasa el tiempo y hasta la segunda guerra mundial (1945), no solo porque la libertad como mera formalidad, en favor de personas individualmente considerada, está vaciada de contenido, sino porque a medida que avanza el tiempo, los liberales comienzan a abandonar la doctrina del derecho natural como fundamento de los derechos humanos y lo único que prevalece es el derecho positivo, donde lo que interesa es defender la ley, sin ningún tipo de valoración (formalismo jurídico) con lo cual comienzan a desaparecer los derechos fundamentales, sustituidos por los derechos públicos subjetivos, producto de la doctrina alemana del derecho público. A esto se suma la aparición de doctrinas alternativas al derecho natural, como por ejemplo el historicismo y las dificultades en Europa para imponer la Constitución por encima del parlamento, unido al surgimiento de movimientos alternativos al liberalismo, como el movimiento democrático, que lucha más por la democracia participativa, junto con el movimiento socialista, que insiste en la igualdad material y en los derechos sociales, lo que se va a plasmar en textos constitucionales de países como México (Constitución de Querétaro de 1917), la Alemania de Weimar y la España de la II república.

Con la llegada de Hitler al poder, y lo que el fascismo significó para la humanidad, se va a tomar conciencia de la necesidad de reforzar el constitucionalismo y de retomar la importancia material de los derechos humanos como fundamento y razón de ser del poder público, al que deben someterse todas sus ramas, de ahí que tanto la Constitución Italiana de 1947 como la Ley Fundamental de Bonn de 1949 consagren preceptos irreformables (cláusulas de intangibilidad),

9 Declaración de Derechos del Pueblo de Virginia (12 de junio de 1776), http://goo.gl/fKLiOk 
así como tribunales constitucionales con competencia para declarar la inconstitucionalidad de la leyes y una amplia carta de derechos a su interior, lo que posteriormente se reflejará en buena parte de las cartas políticas de los países del mundo.

En el contexto de la posguerra cabe destacar también el gran avance alcanzado con la Declaración Universal de los Derechos Humanos de 1948, aprobada por 58 Estados que conformaban la recién Fundada Asamblea General de las Naciones Unidas. Dicha declaración va a tener gran acogida y posterior desarrollo en una serie de instrumentos internacionales de carácter vinculante para los Estados firmantes, junto con el surgimiento de otras instituciones regionales de alto impacto, como el Consejo de Europa y la Organización de Estados Americanos, OEA.

Adelantando una definición, podemos decir entonces que "los derechos humanos son demandas de abstención o actuación, derivadas de la dignidad de la persona y reconocidas como legítimas por la comunidad internacional, siendo por ello merecedoras de protección jurídica por el Estado." 10

En esta definición sobresalen varios elementos: En primer lugar se trata de demandas de acción positiva o de abstención (libertad negativa), de no intervención arbitraria contra la persona misma, bien sea que provenga de una persona pública o privada. En segundo lugar, dichas demandas se derivan de la dignidad humana como valor moral de carácter general que sirve de fundamento a todos los demás derechos. Lo que significa que cuando se demanda la protección de los derechos humanos es porque en el fondo está comprometida la existencia de la persona misma, lo que se traduce en una exigencia ética a favor del ser humano, que, independiente de su condición o procedencia, constituye un valor en sí mismo, por lo cual no debe ser cosificado ni instrumentalizado; pero además se trata, en tercer lugar, de una demanda, a partir de principios y valores reconocidos ampliamente por el derecho internacional, de ahí que sea una insistencia de la comunidad mundial en favor de la libertad y en contra de cualquier agresión externa, pero también una exigencia por las condiciones materiales que las hagan posible; por lo que hoy resulta indiscutible el carácter de derechos humanos de los derechos sociales. Finalmente, estas demandas han logrado o aspiran a lograr protección dentro de los ordenamientos jurídicos, mediante mecanismos, avalados por los Estados, que garanticen su eficacia.

10 Ibíd., 10. 


\section{La perspectiva igualitarista defendida por Erns Tugendhat frente a los Derechos Humanos}

Actualmente los Derechos Humanos han pasado por una serie de debates en torno a su contenido y fundamentación. Así, se han defendido posturas que encuentran su razón de ser en la racionalidad intersubjetiva, propia de una ética comunicativa, como lo hace Habermas, o aquellas que se centran en su contenido material y abogan por una concepción liberal de Estado Mínimo, como ocurre con Hayek, pasando por quienes permiten algunos niveles de justicia material, como Rawls, o las que defienden un Estado activo a favor de las necesidades básicas, teniendo en cuenta las condiciones históricas del ser humano y combinando lo mejor de la tradición liberal con el socialismo, como lo hace la escuela de Budapest. ${ }^{11}$

Ahora bien, en un país como Colombia, signado por tantas disparidades sociales, con pocas o nulas posibilidades reales de participación de las amplias mayorías en la construcción de su futuro, con un Estado débil en la configuración desde sus orígenes ${ }^{12} \mathrm{y}$ con un régimen político caracterizado por el clientelismo, la corrupción, la penetración del narcotráfico y los grupos armados en los espacios de decisión política, así como por su responsabilidad directa, en muchos casos, de violación sistemática a los derechos Humanos o en la omisión de su deber de protegerlos y garantizarlos, vale la pena repensar el paradigma de los Derechos Humanos en clave del igualitarismo defendido por Ernst Tugendath, en el que se les asume como la puerta de entrada a mayores niveles de libertad, capacidad y oportunidad, en otras palabras, como la vía más expedita para la construcción de una sociedad menos violenta, más democrática y con mayores niveles de justicia material, sobre la base del respeto a la dignidad humana.

La discusión en torno a los derechos humanos como base para la construcción de una paz duradera y confiable, en el marco de la Constitución Política, debe, a nuestra manera de ver, enmarcarse en el problema más amplio en torno a los mecanismos que se deben adoptar por parte del Estado para garantizar a los colombianos y colombianas el disfrute de la libertad y para lo cual cumple un papel fundamental la Universidad.

11 Ibíd., 15.

12 Joan Prats Catalá, Gobernabilidad y globalización. Instituciones, políticas y gerencia social en La investigación en administración pública hoy. (Bogotá: ESAP, 1988). 
Inicialmente, la libertad, siguiendo a Ernest Tugendhat ${ }^{13}$, fue considerada como un asunto de autodeterminación, de autonomía, de no coacción. Digamos que la expresión más clara de la coacción frente a un sujeto se presenta con la esclavitud en el mundo antiguo o en el régimen instaurado por Espańa en América, puesto que el esclavo era considerado como una cosa, carente de derechos y libertades, a quien se le podía quitar la vida o marcar, como se marca al ganado. Digamos que cuando la revolución francesa se refirió a las libertades, en la Declaración de los Derechos del Hombre y del Ciudadano de 1789, como ya se seńaló arriba, lo que hizo fue reivindicar la autonomía del sujeto de derechos, como alguien con capacidad para autodeterminarse sin verse coaccionado por otro. Así fue entendida la libertad. La libertad como no coacción.

No obstante, hoy en día la mayoría de los pueblos del mundo al consagrar en sus cartas políticas la fórmula Estado Social de Derecho — como es el caso, por ejemplo, de Colombia, que estableció en su artículo $1^{\circ}$ que "Colombia es un Estado social de derecho, organizado en forma de República unitaria, descentralizada, con autonomía de sus entidades territoriales, democrática, participativa y pluralista, fundada en el respeto de la dignidad humana, en el trabajo y la solidaridad de las personas que la integran y en la prevalencia del interés general.," 14 — lo hizo entendiendo la libertad bajo una perspectiva que va más allá de la no coacción, como bien la entiende Tugenthat. Dicha perspectiva parte de la convicción de que la libertad no se puede reducir simplemente a la no coacción, y que el papel del Estado no consiste solo en garantizar a todos sus asociados el libre disfrute de las libertades individuales como la vida, la libertad de expresión, la intimidad, la correspondencia, la locomoción etc., sino que para que una persona sea efectivamente libre requiere, además de la no coacción, de un amplio desarrollo de sus capacidades y del disfrute de oportunidades para participar de la vida social y política.

Para ilustrar esto, pensemos, como lo hace Tugendhat, en una persona parapléjica que se encuentra postrada en una cama sin poder sobreponerse a la limitación física en la que se encuentra. Se puede decir de ella que su libertad se halla limitada, pero esa limitación no obedece a la acción de otro, como sí ocurre en Grecia o en América con el esclavo. Todo se debe a un designio de la naturaleza y la única posibilidad que tiene de ampliar su grado de libertad es mediante la superación de esa condición natural a través, por ejemplo, de terapias de rehabilitación.

13 Ernest Tugenhat, Liberalismo, libertad y el asunto de los derechos humanos económicos, en Ser, verdad y acción: Ensayos filosóficos (Barcelona: Gedisa, 1988).

14 Constitución Política de Colombia, Artículo $1^{\circ}$. 
De otro lado, pensemos, como lo ilustra Tugendhat, en una situación totalmente distinta: la del escalador experto que ha caído a una grieta sin poder salir de ella a menos que alguien llegue a auxiliarle. Tampoco podría afirmarse que esta persona se encuentra coaccionada por otra o que carece de capacidades para este tipo de deportes, pues se trata de un escalador profesional en su campo. El problema que afronta este individuo consiste en que a pesar de que nadie ejerce una fuerza coactiva y directa sobre él, y a pesar de contar con amplias capacidades para su actividad deportiva, no cuenta con oportunidades para salir de la grieta. Allí en la grieta sus posibilidades de existencia están prácticamente clausuradas.

Con la figura del esclavo, del parapléjico y del escalador que nos propone Tugendhat podemos pensar que la Constitución Política de 1991 consagró en el capítulo $1^{\circ}$ Título II todo un tratado de derechos y libertades: libertad de expresión, libertad de cultos, libre desarrollo de la personalidad, opinión, conciencia etc., en últimas, la consagración de una serie de derechos o principios alrededor de la no coacción a la persona humana, herederos de la vieja tradición iusnaturalista. Son principios en el sentido de que nadie nos puede obligar a ir en contra de ellos, ni pueden ser trasgredidos por las autoridades, negociados, o renunciados por ningún individuo y en ese sentido podríamos decir que en situaciones normales, los colombianos que no han sido víctimas de la violencia, de la intimidación o del desplazamiento forzado, gozan de esas libertades formales, no así los millones de víctimas que deja el conflicto armado en el país y que requieren de un fuerte trabajo para que puedan recuperar la confianza en la sociedad y el Estado, bajo los presupuestos de verdad, justicia y reparación del daño y la garantía de no repetición, a fin de que el horror de la coacción se vaya borrando de la mente de millones de hombres y mujeres.

Sin embargo, resulta indiscutible que la posibilidad de ampliar esas demandas de libertad requiere de una serie de elementos adicionales, sin los cuales esas libertades formales carecerían de sentido y se convertirían en una fórmula vacía. Así por ejemplo, el derecho a la vida, consagrado en el artículo once de la carta política ${ }^{15}$, requiere a la vez de la garantía de unos mínimos en alimentación, vivienda, salud y otros derechos por parte del Estado, cuando la persona o grupo se encuentra en circunstancias de debilidad manifiesta por sus condiciones físicas, psíquicas o económicas que le impiden su subsistencia, pero sobre todo el desarrollo de capacidades que le permitan valerse por sí misma como el parapléjico que se rehabilita. En este desarrollo de capacidades juega un papel estratégico la implementación de una política clara que garantice una educación amplia en calidad y cobertura para todos los colombianos. Así pues, las libertades formales de las que hablábamos solo cobran sentido si los colombianos pueden efectivamente

15 Ibíd., Artículo $11^{\circ}$. 
ejercerlas y eso en muchos casos solo es posible mediante una acción decidida del Estado en favor de una redistribución de los recursos que haga posible la justicia material.

\section{Hacia un igualitarismo en la Colombia del postconflicto impulsada desde la educación superior}

Aquí quiero, entonces, que nos detengamos a pensar en el papel de la educación en el desarrollo y garantía de la autonomía, las capacidades y las libertades de las personas desde la educación entendida como la puerta de entrada a la realización de los derechos humanos y en la universidad como su garante.

Es claro que la educación nos prepara para participar de la vida social, económica y política y para servirnos de los bienes de la cultura mediante su comprensión y transformación. Así mismo, la educación bien entendida cumple la maravillosa función de formar seres humanos con capacidad para resolver sus conflictos de un modo racional en el que podamos vivir juntos sin eliminarnos ni excluirnos. Gracias al universo simbólico en el que nos forma, el ser humano logra superar su condición animal e integrar el núcleo social al que pertenece. La educación no solo nos capacita para comprender el mundo, sino para transformarlo y transformarnos, para convertirnos en miembros de la sociedad y aprovechar sus posibilidades y oportunidades. Sujetos más educados tendrán siempre más oportunidades de participar de la cultura, la ciencia, la tecnología, el mercado etc., y hacer del mundo un espacio más placentero y tolerante.

Así lo entendió la Corte Constitucional, cuando en sentencia de Tutela T-202 de 2000, citado a su vez por la Sentencia T-642 de 2001, señaló que

El derecho a la educación pertenece a la categoría de derechos fundamentales, pues su núcleo esencial comporta un factor de desarrollo individual y social con cuyo ejercicio se materializa el desarrollo pleno del ser humano en todas sus potencialidades. Este derecho constituye un medio para que el individuo se integre efectiva y eficazmente a la sociedad; de allí su especial categoría que lo hace parte de los derechos esenciales de las personas en la medida en que el conocimiento es inherente a la naturaleza humana. La educación está implícita como una de las esferas de la cultura y es el medio para obtener el conocimiento y lograr el desarrollo y perfeccionamiento del hombre. La educación, además, realiza el valor y principio material de la igualdad que se encuentra consignado en el Preámbulo y en los artículos 5, 13, 67, 68 y 69 de 
la C.P. En la medida que la persona tenga igualdad de probabilidades educativas tendrá igualdad de oportunidades en la vida para efecto de realizarse como persona. ${ }^{16}$

Educar para la libertad debe continuar siendo nuestro principal reto desde la universidad, solo de esta manera lograremos mayores niveles de oportunidad e igualdad, pues ya casi nadie discute que la libertad implica a su vez igualdad o, mejor, que la igualdad es una forma de libertad. Pero una perspectiva de igualdad no como en su momento la entendió el liberalismo o como hoy se defiende desde el modelo neoliberal, cuando se considera de forma abstracta que el mejor asignador de los recursos en una economía es el mercado y se lanza a millones de ciudadanos a una competencia ciega, asumiendo que todos poseen las mismas capacidades y oportunidades, he ahí la gran falacia de Friedman y Hayek, defensores de este modelo, como lo advierte Tugendhat. Por el contrario una lectura crítica de la Constitución de 1991 supone entender la igualdad, en sentido aristotélico, como la voluntad permanente de tratar de modo igual a quien es igual y de modo desigual a quien es desigual al afirmar que:"Por ejemplo, parece que la justicia consiste en igualdad, y así es, pero no para todos, sino para los iguales; y la desigualdad parece ser justa, y lo es en efecto, pero no para todos, sino para los desiguales." 17

Ahora bien, si se compara su planteamiento con el artículo 13 de nuestra Constitución cuando señala que:

Todas las personas nacen libres e iguales ante la ley, recibirán la misma protección y trato de las autoridades y gozarán de los mismos derechos, libertades y oportunidades sin ninguna discriminación por razones de sexo, raza, origen nacional o familiar, lengua, religión, opinión política o filosófica.

El Estado promoverá las condiciones para que la igualdad sea real y efectiva y adoptará medidas en favor de grupos discriminados o marginados.

El Estado protegerá especialmente a aquellas personas que por su condición económica, física o mental, se encuentren en circunstancia de debilidad manifiesta y sancionará los abusos o maltratos que contra ellas se cometan. ${ }^{18}$

16 Corte Constitucional, Sentencia T-642 de 2001. (Bogotá, 2000), http://goo.gl/7e2QOQ (16 de octubre de 2014).

17 Aristóteles, Politica III 9 (1280a) citado por la Sentencia C-022 de 1996 M.P.

18 Op. Cit., Constitución Política de Colombia, Artículo $13^{\circ}$. 
Se concluye entonces que lo que quiso el constituyente del 91 fue consagrar la igualdad entendida como una discriminación positiva en favor de las personas o grupos humanos que se encuentren en circunstancias de debilidad manifiesta y esa discriminación positiva debe desarrollarse de manera clara en la ley y sobre todo en las políticas públicas. Es allí donde cobra sentido la universidad como gestora de la masa crítica de la sociedad e impulsora de mayores espacios de libertad para los colombianos, no solo mediante la exigencia clara ante los poderes públicos por la superación de todas las formas de coacción y violación de las libertades que aun atemorizan a las personas en muchas regiones, sino mediante el desarrollo de una academia centrada en los derechos humanos, que se comprometa seriamente con el desarrollo del país a través de la investigación, la docencia y la proyección social.

De ahí que nos corresponda pensar la universidad como un espacio para la investigación de los grandes problemas que aquejan a la sociedad en todos sus aspectos, pero no como una institución cerrada y exclusiva de especialistas, sino como un lugar en el que las comunidades, junto con el sector público y privado, puedan participar de manera activa en la búsqueda de posibles soluciones. Es desde ese esfuerzo por resolver nuestros problemas más apremiantes que cobra sentido la docencia entendida no como un ejercicio de transmisión y reproducción de contenidos producidos en otras latitudes y contextos, sino de cara a las necesidades de la comunidad desde la que provienen sus mismos estudiantes y a la cual debe volver en un ejercicio serio y comprometido de proyección social en la búsqueda de realización y transformación de la persona y el grupo social al que pertenece. De esta forma la investigación, la docencia y la proyección social se convierten en tres elementos distintos pero indisociables en la tarea encomendada a la universidad como institución para pensar y transformar el país.

Lo anterior implica que la universidad se pregunte: ¿cómo negociar su propia agenda con la agenda política del gobierno, la empresa privada y las comunidades para construir juntos el país que queremos más allá de la dispersión y del monopolio del saber y del poder?, ¿cómo aprovechar ese cuarto de hora que tenemos los colombianos para lograr inaugurar una nueva época que supere los temores y los odios y abra un nuevo camino de esperanza y dignidad para todos? 


\section{Referencias}

Amnesty International, The Human Rights Situation in Colombia: Amnesty International's written statement to the 25th. session of the UN Human Rights Council (3-28 March 2014), https://www. amnesty.org/es/library/asset/AMR23/008/2014/es/9cc8391b-1316-4b2f-8df2\%20ae5106532c0c/ amr230082014en.pdf

Aristóteles, Política III 9 (1280a), citado por la Sentencia C-022 de 1996 M.P.

Constitución Política de Colombia, Artículo $1^{\circ}$, Artículo $11^{\circ}$, Artículo $13^{\circ}$.

Corte Constitucional, Sentencia T-642 de 2001. (Bogotá, 2000), http://goo.gl/7e2QOQ (16 de octubre de 2014).

Declaración de Derechos del Pueblo de Virginia (12 de junio de 1776), http://goo.gl/fKLiOk (27 de noviembre de 2014)

Mardones, José. Filosofía de las Ciencias Humanas y Sociales. Materiales para una fundamentación científica. Barcelona: Anthropos, 1982.

Pokrovsky Viktor, (Carlos Marín, Trad.), Historia de las ideas politicas (México: Grijalbo, 1966)

Prats Catalá, Joan. Gobernabilidad y globalización. Instituciones, politicas y gerencia social en La investigación en administración pública hoy. Bogotá: ESAP, 1988).

Programa Regional de Apoyo a las Defensorías del Pueblo en Iberoamérica consultado el 26 de noviembre de 2014 en http://cursos.pradpi.org

Sen, Amartya. Desarrollo como libertad. Madrid: Editorial Planeta, 2000.

Tugenhat, Ernest. Liberalismo, libertad y el asunto de los derechos humanos económicos, en Ser, verdady acción: ensayos filosóficos. Barcelona: Gedisa, 1988. 
